Eixo Temático: Desenvolvimento de Estratégias Didáticas

ET-07-018

\title{
HISTÓRIAS EM QUADRINHOS COMO FERRAMENTAS NO ENSINO DE EDUCAÇÃO AMBIENTAL
}

Pedro Jusselino Netoํㅡ, Marilia Carolina Pereira da Paz¹, Pedro Jusselino Filho², Ronilson José da $\mathrm{Paz}^{3}$

${ }^{1}$ Discente. Curso de Licenciatura Plena em Ciências Biológicas. Universidade Federal da Paraíba. Centro de Ciências Exatas e da Natureza. João Pessoa-PB. (CEP 58051-900).

${ }^{2}$ Docente. Departamento de Fundamentação da Educação. Centro de Educação. Universidade Federal da Paraíba. João Pessoa-PB. (CEP 58051-900). E-mail: pedro.jusselino.filho@gmail.com.

${ }^{3}$ Docente. Escola de Ensino Fundamental Gonçalves Dias. Analista Ambiental do IBAMA-PB. Caixa Postal 5063. João Pessoa-PB. (CEP 58051-900). E-mail: ronilson.paz@gmail.com.

$$
\text { http://dx.doi.org/10.21472/congrebio2016.et-07-018 }
$$

\section{RESUMO}

O presente estudo disute a utilização de história em quadrinhos como ferramenta didática complementar no ensino de Educação Ambiental, de modo que favoreça positivamente o processo ensino-aprendizagem, aumentando o envolvimento e o interesse dos docentes nos conteúdos transmitidos na sala deaula. Para a primeira proposta, foi relatado como o descarte inadequado de resíduo sólido (uma tampa de garrafa) pode causar transtorno à biota aquática, alertando para a necessidade do correto descartes desse material. Acredita-se que o uso dessa metodologia, além de facilitar a transmissão dos conhecimentos, possibilitará maior efetividade nas interações entre docentes e discentes, tendo em vista que a apredizagem fluirá entre os participantes do processo, sem que haja imposição, transformando a sala de aula num constante fluxo prazeroso de informação.

Palavras-chave: Educação Ambiental; Novas metodologias de ensino. Histórias em quadrinhos.

\section{INTRODUÇÃO}

O principal objetivo da educação é a produzir mudanças no comportamento de modo que o sujeito posso reconhecer o ambiente em que vive e posso sugerir, propor e provocar modificações positivas que garantam a integridade do ambiente em que vivem. Cabe à Educação Ambiental formar uma população mundial consciente e preocupada com o meio ambiente e com os problemas a ele relacionados, e que tenha conhecimento, aptidão, atitude, motivação e compromisso para trabalhar individual e coletivamente na busca de soluções para os problemas existentes, bem como para previnir novos (PAZ, 2006).

Para colimar esses objetivos, é necessário que o professor, conscio de suas responsabilidades, que não são poucas, tampouco simples, procure metodologias e ferramentas que tornem as aulas mais atrativas e prazeirosas de modo que facilitem a apredizagem e a transmissão do conhecimento flua de modo mais eficiente e eficaz.

Essas ferramentas, além de facilitar o acesso aos novos conhecimentos servem também de base para novas adaptações aos sistemas variados de transmissão de conhecimento, de maneira a melhorar, transferir e transformar os fatores complicados em algo mais acessível e sedimentado, transformando a teoria em prática (SOUZA e SOUZA, 2010). As novas 
tecnologias ajudam de forma efetiva o aluno em sala de aula, estimulando a melhoria de seu desempenho.

Outro ponto positivo das novas metodologias educacionais é a possibilidade mais efetiva de interação entre docentes e discentes, tendo em vista que a apredizagem flui entre os participantes do processo sem que seja algo impositivo, transformando a sala-de-aula numa constante fluxo de informação.

Considerando que as histórias em quadrinhos, assim como charges e tirinhas são produtos da cultura de massa, veiculados constantemente em jornais, revistas, livros didáticos e na internet (CUNHA et al., 2014), elas servem de apoio pedagógico que devem ser usadas para motivar os educandos em sala-de-aula. Dando condições para que o aluno vivencie o método científico, que ao partir de suas observações, possa levantar hipóteses, testá-las, refutá-las e abandoná-las quando for o caso, trabalhando de forma a redescobrir os conhecimentos (LOPES e PLATZER, 2013).

Com esse propósito, as histórias em quadrinhos foram usadas nas aulas de Biologia (BANTI, 2012; COSTA, 2013; CUNHA et al., 2014) e de Ciências (CARVALHO e MARTINS, 2009; BANTI, 2012; SILVA et al., 2014; MOLINA e FONSECA, 2014; CAVALCANTE et al., 2015), demonstrando que a utilização desse recurso didático há muito tempo vem chamando a atenção dos docentes.

Esse trabalho tem como objetico demonstrar que a utilização de histórias em quadrinhos pode ser utilizado nas transmissão de conhecimento de Educação Ambiental.

\section{METODOLOGIA}

A sistemática de construção da história em quadrinho foi realizada pelo próprio grupo de pesquisa, formado por alunos de graduação e professores de Biologia. A primeira versão foi construída de modo a relatar como o descarte inadequado de resíduo sólido (uma tampa de garrafa pet no continente) pode causar transtorno à biota aquática (cuasando morte de tartaruga marinha no oceano), alertando para a necessidade do correto descartes desse material.

Com base nos argumentos apresentados pelo grupo, ficou ao cargo do primeiro autor a criação artística dos quadrinhos.

Outros temas de interesse dos Programas de Educação Ambiental, como combustíveis alternativos e renováveis, efeito estufa, chuva ácida, buraco na camada de ozônio, tráfego de animais silvestres, combate à dengue e a outras doenças tropicais. A possibilidades são inúmeras, a depender da criatividaade dos participantes.

\section{CONSIDERAÇÕES FINAIS}

Acredita-se que o uso dessa metodologia, além de facilitar a transmissão dos conhecimentos, possibilitará maior efetividade nas interações entre docentes e discentes, tendo em vista que a apredizagem fluirá entre os participantes do processo, sem que haja imposição, transformando a sala de aula num constante fluxo prazeroso de informação.

Ademais, do mesmo modo que Silveira e Caruso (2009) e Cavalcante et al. (2015), acredita-se que as histórias em quadrinhos na Educação Ambiental pode contribuir para a A formação de cidadãos mais críticos, reflexivos e conscientes de seus direitos e deveres, proporcionando-lhes habilidades que colaborarão nas práticas cotidianas no que diz respeito à questão ambiental. 


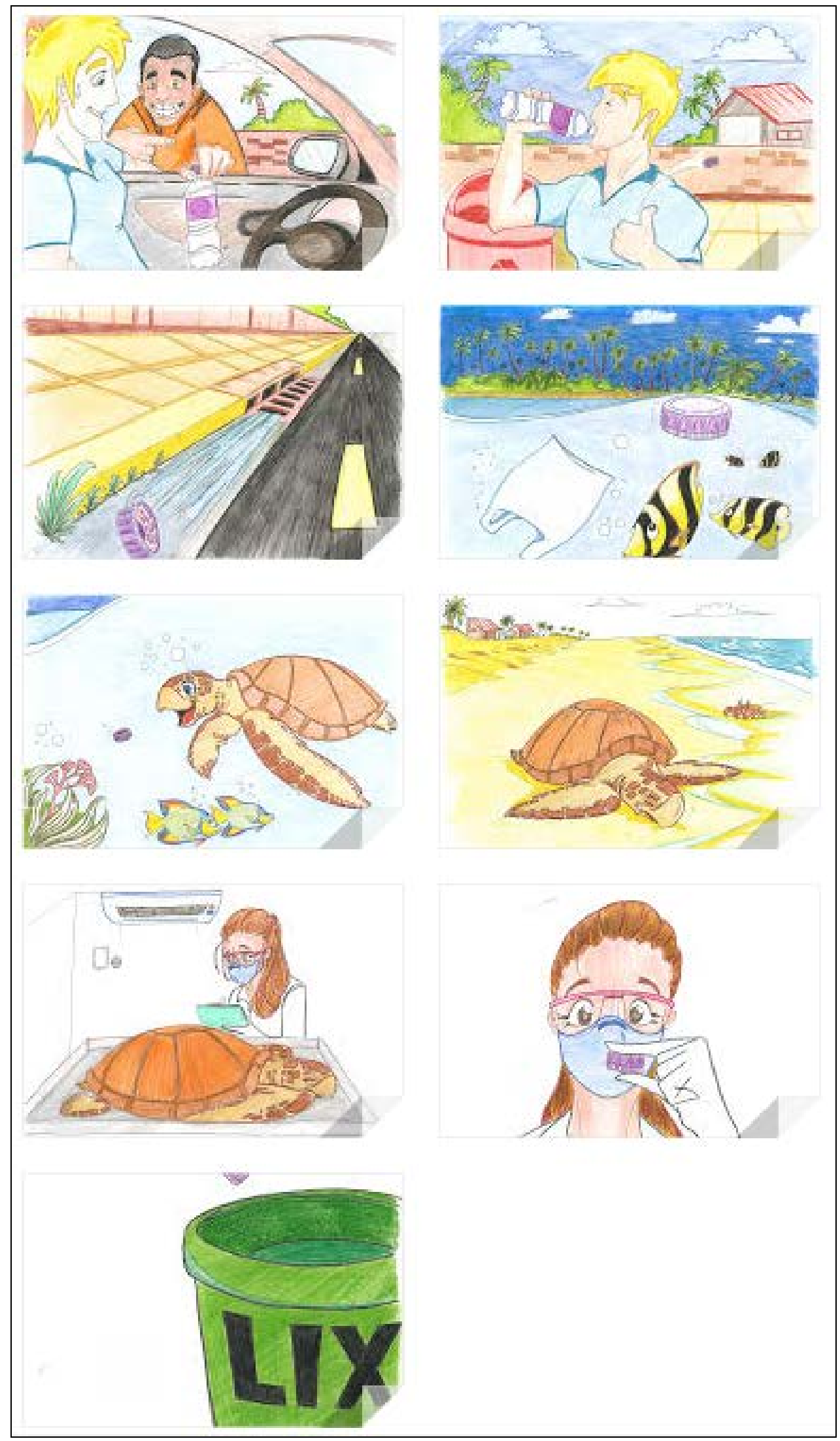

Figura 1. Quadrinhos produzidos a partir de um enredo sobre a destinação inadequada de uma tampa de garrafa plástica. 


\section{REFERÊNCIAS}

BANTI, R. S. A utilização das História s em Quadrinhos no Ensino de Ciências e Biologia. São Paulo: Universidade Presbiteriana Mackenzie, 2012. (Monografia de graduação).

CARVALHO, L. S.; MARTINS, A. F. P. Os quadrinhos nas aulas de Ciências Naturais: uma história que não está no gibi. Revista Educação em Questão, v. 35, n. 21, p. 120-145, 2009. Disponível em: <https://periodicos.ufrn.br/educacaoemquestao/article/viewFile/3959/3226>. Acesso em: 21 mar. 2016.

CAVALCANTE, K. S. B.; SILVA, F. C.; MACIEL, A. P.; LIMA JÚNIOR, J. A. S.; RIBEIRO, J. S. S.; SANTOS, P. J. C.; PINHEIRO, A. E. P. Educação Ambiental em histórias em quadrinhos: Recurso didático para o ensino de Ciências. Química Nova na Escola, v. 37, n. 4, p. 270-277, 2015. http://dx.doi.org/10.5935/0104-8899.20150049

COSTA, A. B. S. História em quadrinhos e ensino de Ciências: tiras da Revista Níquel Náusea na aprendizagem da Teoria Evolutiva. Niterói: Universidade Federal Fluminense, 2013. (Monografia de graduação).

CUNHA, A. L. R. S.; ALVES, J. M.; ALMEIDA, A. C. P. C. A motivação discente em aulas de Biologia com quadrinhos. Revista da SBEnBio, n. 7, p. 604-616, 2014. Disponível em: <http://www.sbenbio.org.br/wordpress/wp-content/uploads/2014/11/R0460-2.pdf>. Acesso em: 21 mar. 2016.

LOPES, M. M.; PLATZER, M. B. O uso de recursos didáticos como estratégia no ensino de Ciências e Biologia. Revista Uniara, v. 16, n. 1, p. 173-182, 2013. Disponível em: $<$ http://www.uniara.com.br/legado/revistauniara/pdf/30/artigo_14.pdf $>$. Acesso em: 21 mar. 2016.

MARTINS, E. K. Histórias em quadrinhos no ensino de ciências: uma experiência para o ensino do Sistema Nervoso. Ponta Grossa: Universidade Tecnológica Federal do Paraná, 2012. (Dissertação de mestrado).

MOLINA, J.; FONSECA, J. Dengue: o confronto definitivo. João Pessoa: Grafeset, 2014.

PAZ, R. J. Meio ambiente, ecologia e ensino. In: PAZ, R. J. (Org.). Fundamentos, reflexões e experiências em Educação Ambiental. João Pessoa: Editora Universitária/UFPB. 2006. p. 19-41.

SILVA, C. R. P.; OLIVEIRA, C. D. L.; CAMPOS, R. S. P. A prática pedagógica e a história em quadrinhos no ensino de Ciências. Revista da SBEnBio, n. 7, p. 1090-1097, 2014. Disponível em: <http://www.sbenbio.org.br/wordpress/wp-content/uploads/2014/11/R0029-1.pdf>. Acesso em: 21 mar. 2016.

SILVEIRA, C.; CARUSO, F. Quadrinhos para a cidadania. História, Ciência, Saúde $\begin{array}{lllll}\text { Manguinhos, } & \text { v. 16, } & \text { n. 1, } & \text { p. 217-236, } 2009 . & \text { Disponível em: }\end{array}$ $<$ http://www.scielo.br/pdf/hcsm/v16n1/13.pdf>. Acesso em: 21 mar. 2016.

SOUZA, I. M. A.; SOUZA, L. V. A. O uso da tecnologia como facilitadora da aprendizagem do aluno na escola. Revista Fórum Identidades, v. 8, n. 8, p. 127-142, 2010. Disponível em: $<$ http://seer.ufs.br/index.php/forumidentidades/article/view/1784/1573>. Acesso em: 21 mar. 2016. 